\title{
CARDIAC BIOMARKERS IN PREMATURE CALVES WITH RESPIRATORY DISTRESS SYNDROME
}

\author{
Ugur Aydogdu $^{1}$, Ramazan Yildiz ${ }^{2}$, Hasan GuZELBEKTEs ${ }^{3,4}$, Alparslan CosKuN $^{1}$ \\ and Ismail $\mathrm{SEN}^{4 *}$
}

${ }^{1}$ Department of Internal Medicine, Faculty of Veterinary Medicine, Cumhuriyet University, Sivas, Turkey; ${ }^{2}$ Department of Internal Medicine, Faculty of Veterinary Medicine, Mehmet Akif Ersoy University, Burdur, Turkey; ${ }^{3}$ Department of Internal Medicine, Faculty of Veterinary Medicine, Kyrgyz Turkish Manas University, Bishkek, Kyrgyzstan; ${ }^{4}$ Department of Internal Medicine, Faculty of Veterinary Medicine, Selcuk University, 42075 Konya, Turkey

(Received 28 March 2015; accepted 28 October 2015)

The aim of this study was to determine the clinical relevance of cardiac biomarkers [troponin I and T, creatine kinase-MB fraction (CK-MB) and lactate dehydrogenase $(\mathrm{LDH})]$ in premature calves with respiratory distress syndrome. Seventy premature calves were admitted to the clinic within $24 \mathrm{~h}$ after birth. Respiratory distress syndrome was diagnosed in premature calves by clinical examination and venous blood gas analysis. Ten healthy calves, aged 5 days, were used as control. Cardiac troponin I and T were analysed using ELISA and ELFA, respectively. Serum CK-MB and LDH were also analysed in an automatic analyser. The calves had low venous $\mathrm{pH}, \mathrm{pO}_{2}, \mathrm{O}_{2}$ saturation and high $\mathrm{pCO}_{2}$ values consistent with dyspnoea, hypoxaemia, and inadequate oxygen delivery. Mean serum troponin I, troponin T, CK-MB and LDH levels were increased in the premature calves compared to the control group. In conclusion, the results in this study demonstrated that serum CK-MB, troponin I and troponin T concentrations could be used for evaluating myocardial injury in premature calves with respiratory distress syndrome.

Key words: Premature calves, cardiac biomarkers, respiratory distress syndrome

Early birth that occurs before the end of the normal pregnancy period of cows is called premature birth. This period is between days 250 and 270 of gestation. Therefore, calves born earlier than 270 days are called premature calves which need specific nursing, feeding and care to keep them alive (Altug and Basbugan, 2013). Morbidity and mortality of premature calves due to immaturity of physiological functions are higher than in calves born at term (Bittrich et al., 2002). Premature calves have surfactant deficiency (Divers, 2008). Insufficient

*Corresponding author; E-mail: ismailsen@selcuk.edu.tr; Phone: 0090 (332) 223-3594; Fax: 0090 (332) 241-0063 
surfactant leads to end-expiratory collapse of lung regions that are inadequately, or not at all, aerated. These atelectatic regions result in inadequate surface area for gas exchange, and the neonate increases its respiratory rate to maintain adequate ventilation. If this is not achieved, hypoxia ensues (Bleul, 2009). In addition, respiratory distress syndrome (RDS) develops together with a progressive respiratory and metabolic acidosis within the first hour of life (Eigenmann et al., 1984). The $\mathrm{pCO}_{2}$ will be elevated in premature calves with RDS, and this can be confirmed by a venous sample ( $>45 \mathrm{~mm} \mathrm{Hg}$ ) (Divers, 2008; Guzelbektes et al., 2012). Term and preterm calves with RDS have high mortality because of hypoxia, hypercapnia, and acidosis (Pickel et al., 1989; Szenci et al., 1989). Hypoxia results from impaired oxygen delivery to cells and decreased tissue perfusion. Therefore, hypoxia may affect cardiac function. Cardiac biomarkers are used to identify cardiac disease in humans and animals (Undhad et al., 2012; Vijlbrief et al., 2012). Cardiac enzymes including lactate dehydrogenase (LDH) and creatine kinase-MB fraction (CK-MB), as well as troponins are used in the determination of cardiac injury (Kemp et al., 2004). LDH is found in a wide variation of tissues and is most abundant in liver, kidney, muscle, and myocardium (Radostits et al., 2007; Russell and Roussel, 2007). CK-MB is a biochemical marker which has been used for the detection of acute myocardial infarction for a long time. In humans and animals, CK-MB is found predominantly in the myocardium, with concentration ranges from 5 to $30 \%$ of the total CK activity of the heart. Cardiac troponins (cTn) have a high sensitivity and specificity for myocardial injury. Troponin consists of three subunits: troponin I (cTn-I), troponin $\mathrm{T}(\mathrm{cTn}-\mathrm{T})$, and troponin $\mathrm{C}$. Troponin $\mathrm{T}$ and I are ideal diagnostic markers for myocardial injury since the heart and extracardiac muscle express distinct isoforms which are encoded by different genes (El-Khuffash and Molloy, 2008; Undhad et al., 2012). Owing to the positive correlation between the concentration of troponin and the size of myocardial injury developing after cardiac surgery or cardiotoxic drug treatment, troponin is useful as a prognostic indicator of mortality and morbidity in the paediatric age group. The same principle applies to term and preterm newborns in RDS for evaluating the extent of myocardial injury ( $\mathrm{Ng}$ and Lam, 2012). Based on the similarity of clinical signs and pathological findings, it is thought that the mechanisms underlying RDS in infants and calves are very similar. Until now, there has been no study on cardiac biomarkers in premature calves suffering from hypoxia, although there are many reports in preterm infants. Therefore, the aim of this study was to determine the clinical relevance of cardiac biomarkers (troponin I and T, CK-MB and LDH) in premature calves with RDS. 
AYDOGDU et al.

\section{Materials and methods}

Animals

This study was conducted in the Large Animal Hospital of the Faculty of Veterinary Medicine of Selcuk University. Seventy premature calves were admitted to the Large Animal Hospital for treatment. The premature calves had a gestational age between 230 to 260 days, low body weight, weak or no suckling reflex, short silky hair coat, soft claw, general weakness, inability to stand, and incomplete eruption of the incisor teeth. Premature calves had also $\mathrm{RDS}\left(\mathrm{pCO}_{2}>\right.$ $58 \mathrm{~mm} \mathrm{Hg}$, respiratory acidosis, and tachypnea). All calves were admitted to the clinic within 12 to $24 \mathrm{~h}$ after birth. There were 38 male and 32 female calves. The majority of the calves were of the Swiss Brown breed, with a mean body weight of $26.69 \mathrm{~kg}(17-37 \mathrm{~kg})$ on admission. Ten clinically healthy calves, aged 5 days, were used as control. All premature calves with RDS in this study were grouped according to their $\mathrm{pH}$ values as suggested by Eigenmann et al. (1981): blood $\mathrm{pH}>7.2$ (normal/physiological acidosis $=$ slight, combined respiratory and metabolic acidosis); blood $\mathrm{pH}$ 7.2-7.0 (acidotic $=$ moderate, combined respiratory and metabolic acidosis); blood $\mathrm{pH}<7.0$ (severely acidotic $=$ severe, combined respiratory and metabolic acidosis).

\section{Sample collection and blood analysis}

Blood samples were taken from the jugular vein to measure blood gases and biochemical parameters (cardiac troponin I and T, CK-MB and LDH). Venous blood samples were collected anaerobically from the jugular vein into plastic syringes containing sodium heparin for blood gas analysis, which was performed within 10 min of collection. Syringes used for collecting venous blood for gas analysis were prepared by aspirating a small volume of liquid heparin (5000 IU/ml, Nevparin, Mustafa Nevzat Company, Istanbul, Turkey) and then expelling it. The thin film of liquid heparin that remains coated to the walls of the syringe is sufficient to anticoagulate the blood sample. An aliquot of blood was placed into vacuum glass tubes (BD serum tube, USA) for serum biochemi$\mathrm{cal}$ analysis. The tubes were centrifuged (5000 rpm, $10 \mathrm{~min}$ ) after clotting, and the serum was carefully harvested and stored at $-20{ }^{\circ} \mathrm{C}$ until analysed. The venous blood gases were analysed using an automatic blood gas analyser (GEM Premier 3000, Instrumentation Laboratory, Lexington, MA, USA). Serum CKMB and LDH activities were measured with an automatic analyser (BT 3000 plus, Biotecnical Inc., SPA, Rome, Italy). Serum troponin T level was measured with a commercially available ELISA kit (Bovine Cardiac Troponin T, Cusabio Biotech Co., Ltd., Wuhan, China). The manufacturer of this assay reported a limit of detection in bovine serum of $187.5-3,000 \mathrm{pg} / \mathrm{ml}$. In this kit, an intraassay and inter-assay precision of $<15 \%$ has been reported. The optical density 
of the samples was measured at $450 \mathrm{~nm}$ using a microplate reader (Multiskan ${ }^{\mathrm{TM}}$ Go Microplate Spectrophotometer, Thermo Scientific, USA). Serum troponin I level was measured by an automated quantitative method (VIDAS ${ }^{\circledR}$ Troponin I Ultra, Biomérieux, Marcy-l'Etoile, France) with the Enzyme-Linked Fluorescent Assay technique, and the lower limit for the dosage was $0.01 \mathrm{mg} / \mathrm{L}$. The reportable range of this method is 0.01 to $30 \mathrm{mg} / \mathrm{mL}$.

\section{Statistical analysis}

All data were presented as mean and standard error of mean (mean \pm SEM). The level of statistical significance was $P<0.05$. ANOVA and Tukey's multiple range tests were used to assess differences between the groups. The SPSS software program (Version 15.0, SPSS Inc., Chicago, IL, USA) was used for statistical analyses.

\section{Results}

Respiratory distress syndrome was observed in all premature calves. Clinical examination of all premature calves showed clinical signs of RDS including respiratory insufficiency, apnoea or tachypnea, weakness and depression (Table 1). In addition, lethargy, coma, cyanosis, increased capillary refill time, tachycardia, and hypothermia were observed in the premature calves (Table 1). The calves also had weak or no suckling reflex. All the calves were hospitalised during the treatment period. Fifty-four out of 70 premature calves recovered and were discharged from the hospital in a healthy state. However, 16 premature calves died within 4872 hours after birth.

Table 1

Clinical findings in premature calves with respiratory distress syndrome (RDS) and in control calves

\begin{tabular}{|c|c|c|c|c|}
\hline Parameters & $\begin{array}{c}\text { Premature } \\
\mathrm{pH}<7.00 \\
\mathrm{n}=5 \\
\text { Mean } \pm \text { SEM }\end{array}$ & $\begin{array}{c}\text { Premature } \\
\text { pH: } 7.00-7.20 \\
\mathrm{n}=18 \\
\text { Mean } \pm \text { SEM }\end{array}$ & $\begin{array}{c}\text { Premature } \\
\mathrm{pH} \geq 7.20 \\
\mathrm{n}=47 \\
\text { Mean } \pm \text { SEM }\end{array}$ & $\begin{array}{l}\text { Control calves } \\
\quad(\mathrm{n}=10) \\
\text { Mean } \pm \text { SEM }\end{array}$ \\
\hline Temperature $\left({ }^{\circ} \mathrm{C}\right)$ & $34.6 \pm 0.10^{\mathrm{b}}$ & $35.8 \pm 0.40^{\mathrm{b}}$ & $38.0 \pm 0.16^{\mathrm{a}}$ & $38.5 \pm 0.07^{\mathrm{a}}$ \\
\hline Heart rate/min & $118.4 \pm 19.5^{\mathrm{ab}}$ & $132.8 \pm 10.1^{\mathrm{a}}$ & $141.7 \pm 3.77^{\mathrm{a}}$ & $92.1 \pm 5.34^{\mathrm{b}}$ \\
\hline Respiratory rate/min & $43.2 \pm 4.27^{\mathrm{b}}$ & $45.6 \pm 3.19^{\mathrm{ab}}$ & $60.5 \pm 3.83^{\mathrm{a}}$ & $38.1 \pm 3.02^{\mathrm{ab}}$ \\
\hline Capillary refill time (sec) & $4.40 \pm 0.24^{\mathrm{a}}$ & $4.00 \pm 0.30^{\mathrm{ab}}$ & $3.12 \pm 0.24^{\mathrm{b}}$ & $1.70 \pm 0.21^{\mathrm{c}}$ \\
\hline
\end{tabular}

Differences between values marked with different superscript letters in the same row are statistically significant

The levels of serum troponin I, troponin T, CK-MB, LDH and blood gas parameters in the premature calves and control calves are presented in Table 2. The $\mathrm{pCO}_{2}$ levels increased in premature calves with $\mathrm{RDS}$, whereas $\mathrm{pH}, \mathrm{pO}_{2}$ and 
$\mathrm{O}_{2}$ saturation levels decreased in premature calves compared to control calves. Premature calves had low $\mathrm{pH}$ values $(\leq 7.345)$ compared to the control group (Table 2). Serum troponin I, troponin T, LDH and CK-MB levels of premature calves increased as compared to the control calves (Table 2). However, there were no statistically significant differences in $\mathrm{LDH}$, troponin I and T levels of the premature calves (Table 2).

Table 2

Cardiac biomarkers and blood gas parameters in premature calves with respiratory distress syndrome (RDS) and in control calves

\begin{tabular}{|c|c|c|c|c|}
\hline Parameters & $\begin{array}{c}\text { Premature } \\
\mathrm{pH}<7.00 \\
\mathrm{n}=5 \\
\text { Mean } \pm \text { SEM }\end{array}$ & $\begin{array}{c}\text { Premature } \\
\text { pH: } 7.00-7.20 \\
n=18 \\
\text { Mean } \pm \text { SEM }\end{array}$ & $\begin{array}{c}\text { Premature } \\
\mathrm{pH} \geq 7.20 \\
\mathrm{n}=47 \\
\text { Mean } \pm \text { SEM }\end{array}$ & $\begin{array}{c}\text { Control calves } \\
(\mathrm{n}=10) \\
\text { Mean } \pm \text { SEM }\end{array}$ \\
\hline Troponin-T (pg/ml) & $484.6 \pm 36.8^{\mathrm{ab}}$ & $441.5 \pm 22.9^{\mathrm{ab}}$ & $524.3 \pm 26.3^{\mathrm{a}}$ & $344.8 \pm 19.1^{\mathrm{b}}$ \\
\hline Troponin-I (ng/ml) & $0.80 \pm 0.33$ & $0.47 \pm 0.09$ & $0.87 \pm 0.21$ & $0.03 \pm 0.01$ \\
\hline CK-MB (U/L) & $515.9 \pm 79.6^{\mathrm{a}}$ & $384.1 \pm 59.1^{\mathrm{ab}}$ & $252.4 \pm 21.1^{\mathrm{b}}$ & $211.78 \pm 30.6^{\mathrm{b}}$ \\
\hline LDH (U/L) & $911.0 \pm 100.2$ & $995.5 \pm 116.5$ & $1116.8 \pm 62.5$ & $959.2 \pm 77.0$ \\
\hline $\mathrm{pH}$ & $6.888 \pm 0.035^{\mathrm{d}}$ & $7.103 \pm 0.017^{\mathrm{c}}$ & $7.345 \pm 0.008^{b}$ & $7.425 \pm 0.009^{\mathrm{a}}$ \\
\hline $\mathrm{pCO}_{2}(\mathrm{~mm} / \mathrm{Hg})$ & $90.2 \pm 9.92^{\mathrm{a}}$ & $74.3 \pm 4.43^{\mathrm{b}}$ & $53.0 \pm 1.01^{\mathrm{c}}$ & $42.1 \pm 1.25^{\mathrm{c}}$ \\
\hline $\mathrm{pO}_{2}(\mathrm{~mm} / \mathrm{Hg})$ & $21.4 \pm 5.03^{b}$ & $17.6 \pm 1.93^{\mathrm{b}}$ & $19.8 \pm 0.88^{b}$ & $30.2 \pm 2.86^{\mathrm{a}}$ \\
\hline $\mathrm{O}_{2}$ sat. $(\%)$ & $13.4 \pm 4.78^{b}$ & $13.6 \pm 1.99^{\mathrm{b}}$ & $28.6 \pm 2.01^{\mathrm{b}}$ & $56.7 \pm 6.48^{\mathrm{a}}$ \\
\hline $\mathrm{HCO}_{3}(\mathrm{mmol} / \mathrm{L})$ & $17.0 \pm 1.71^{\mathrm{c}}$ & $23.1 \pm 1.09^{b}$ & $29.2 \pm 0.61^{\mathrm{a}}$ & $27.6 \pm 0.73^{\mathrm{a}}$ \\
\hline $\mathrm{BE}(\mathrm{mmol} / \mathrm{L})$ & $-16.1 \pm 1.79^{\mathrm{c}}$ & $-6.67 \pm 1.12^{\mathrm{b}}$ & $3.38 \pm 0.69^{\mathrm{a}}$ & $3.19 \pm 0.77^{\mathrm{a}}$ \\
\hline
\end{tabular}

Differences between values marked with different superscript letters in the same row are statistically significant. CK-MB: creatine kinase-myocardial band; LDH: lactate dehydrogenase, $\mathrm{pH}$ : concentration of hydrogen ions; $\mathrm{pCO}_{2}$ : partial pressure of carbon dioxide; $\mathrm{pO}_{2}$ : partial pressure of oxygen; $\mathrm{HCO}_{3}$ : bicarbonate; $\mathrm{BE}$ : base excess; $\mathrm{O}_{2}$ sat. \%: oxygen saturation

\section{Discussion}

Respiratory distress syndrome is a condition of neonatal calves, characterised by a deficiency in oxygen uptake and carbon dioxide retention in the blood, as well as interstitial and alveolar oedema (Eigenmann et al., 1984; Bleul et al., 2008). Shortly after birth, premature calves with surfactant deficiency develop respiratory distress and cyanosis. RDS is a group of signs caused by a deficiency of surfactant. Clinical findings about RDS are blood gas abnormalities, hypoxia, inspiratory and expiratory dyspnea (Karapinar and Dabak, 2008; Guzelbektes et al., 2012). In this study, premature calves had clinical signs related to RDS, including low venous $\mathrm{pH}, \mathrm{pO}_{2}$ and $\mathrm{O}_{2}$ saturation and high $\mathrm{pCO}_{2}$ consistent with dyspnoea, hypoxaemia, and inadequate oxygen delivery (Table 2). High alveolar surface tension due to the lack of surfactant is likely to result in extensive alveo- 
lar collapse leading to pulmonary atelectasia, ventilation-perfusion incompatibility, hypoxaemia, hypercapnia, and respiratory acidosis (Christmann et al., 2009).

Neonatal hypoxic ischaemia usually leads to cardiovascular disorders. Oxygen depletion due to secondary hypoxic ischaemia is thought to be caused myocardial injury (Sweetman et al., 2012). Premature infants with RDS have been reported to have low cardiac output and myocardial dysfunction (Gill and Weindling, 1993; Evans and Kluckow, 1996). Cardiac involvement associated with hypoxia in newborns occur in about $29 \%$ of asphyxiated infants (MartinAncel et al., 1995). Many studies indicated that infants with perinatal asphyxia and RDS develop myocardial damage (Tapia-Rombo et al., 2000; Trevisanuto et al., 2000a,b; Szymankiewicz et al., 2006). Unfortunately, there is no information about myocardial damage associated with hypoxia in premature calves with RDS. In this study, all premature calves with RDS were hypoxic due to low $\mathrm{pO}_{2}$ and $\mathrm{O}_{2} \%$ saturation (Table 2). Therefore, we can speculate that myocardial damage should have developed in premature calves due to hypoxia. Szymankiewicz et al. (2006) reported that CK-MB and cTn-T levels increased in asphyxiated infants. In contrast, Möller et al. (1998) reported that in infants with perinatal asphyxia the CK-MB level has no diagnostic value. Mu et al. (2009) demonstrated that there is no significant correlation between cTn-I and CK-MB in neonates with respiratory distress. cTn-T and CK-MB levels were determined to be significantly higher in infants with perinatal asphyxia (Rajakumar et al., 2008). The same group also reported that cardiac troponin $\mathrm{T}$ has high sensitivity and specificity compared to CK-MB. In this study, it was determined that the level of CK$\mathrm{MB}$ was significantly $(\mathrm{P}<0.05)$ increased in premature calves with RDS compared to control calves, whereas LDH activity was less increased. There was no statistical difference in serum LDH in premature calves with RDS compared to the control group. It can be stated that the increase in CK-MB level may be more useful than the rise in LDH activity in evaluating myocardial injury in premature calves with RDS. CK-MB is generally used for the determination of cardiac damage. However, the CK-MB isoenzyme is found in a small but significant amount in the skeletal muscle as well. Therefore, skeletal muscle damage can cause an increase in blood CK-MB levels. Due to the lack of tissue specificity, LDH enzyme activity is considered to have only partial value in the detection of myocardial damage (Kemp et al., 2004).

Cardiac troponins have high sensitivity and specificity for the detection of myocardial injury and are considered to be suitable cardiac biomarkers for the determination of cellular damage (Bader et al., 2006; Wells and Sleeper, 2008). Cardiac injury in cattle has been identified by increased cardiac troponin levels in a variety of diseases that include monensin toxicosis (Varga et al., 2009), traumatic reticulopericarditis (Gunes et al., 2008; Mellanby et al., 2009), footand-mouth disease (Gunes et al., 2005; Karapinar et al., 2010), and endotoxaemia (Peek et al., 2008). The cardiospecific isoenzyme troponin I provides the 
most sensitive and specific indication of cardiac necrosis whereas the predictive value of serum CK and LDH activities is much lower (Radostits et al., 2007). O'Brien et al. (1997b) suggested that troponin I is a good marker in the detection of cardiac damage in all mammalian species. Tunca et al. (2008) reported that cardiac troponin I levels of calves with foot-and-mouth disease increased significantly compared to the control group, and they also stated that increased concentrations of serum troponin I were correlated with myocardial injury. Cardiac troponin $\mathrm{T}$ is a specific marker of myocardial injury in perinatal asphyxia (Sadoh and Eregie, 2012). Clark et al. (2004) found that sick infants with RDS had poor myocardial function, hypotension, and elevated troponin $\mathrm{T}$ levels. Troponin $\mathrm{T}$ is more cardioselective than conventional CK-MB and LDH as a cardiac biomarker, and it is undoubtedly a more precise indicator of cardiac injury $(\mathrm{Ng}$ and Lam, 2012). Trevisanuto et al. (2000a) reported increased levels of cTn-T due to myocardial damage in preterm infants with respiratory distress. Lopes et al. (2012) have reported that cTn-T may be a very useful and early marker of myocardial injury in newborn infants of very low birth weight. O'Brien et al. (1997a) stated that $\mathrm{cTn}$-T was a powerful biomarker for the determination of myocardial injury in laboratory animals. In the present study, we observed that cTn-I and cTn-T levels in premature calves with RDS were increased compared to values in control calves. However, there were no statistically significant differences in troponin I and T levels in the premature groups (Table 2). According to these results, increased serum cTn-I and cTn-T levels could be related to myocardial damage in premature calves with RDS.

In conclusion, the results of this study show that serum troponin I, T and CK-MB levels can be used in the evaluation of myocardial injury in premature calves with RDS. Echocardiographic examinations and studies on cardiac biomarkers are needed for determining cardiac problems in premature calves with RDS.

\section{Acknowledgements}

This study was supported by a grant received from the Scientific and Technological Research Council of Turkey (project number: 1110868) and partly from Selcuk University, Scientific Research Project Office (SUBAP).

\section{References}

Altug, N. and Basbugan, Y. (2013): Premature calves [in Turkish]. Turkiye Klinikleri J. Vet. Sci. 4, 53-61. Bader, D., Kugelman, A., Lanir, A., Tamir, A., Mula, E. and Riskin, A. (2006): Cardiac troponin I serum concentrations in newborns: a study and review of the literature. Clin. Chim. Acta 371, 61-65.

Bittrich, S., Morel, C., Philipona, C., Zbinden, Y., Hammon, H. M. and Blum, J. W. (2002): Physiological traits in preterm calves during their first week of life. J. Anim. Physiol. Anim. Nutr. (Berl.). 86, 185-198. 
Bleul, U. (2009): Respiratory distress syndrome in calves. Vet. Clin. Food. Anim. 25, 179-193.

Bleul, U. T., Bircher, B. M. and Kahn, W. K. (2008): Effect of intranasal oxygen administration on blood gas variables and outcome in neonatal calves with respiratory distress syndrome: 20 cases (2004-2006). J. Am. Vet. Med. Assoc. 233, 289-293.

Christmann, U., Buechner-Maxwell, V. A., Witonsky, S. G. and Hite, R. D. (2009): Role of lung surfactant in respiratory disease: current knowledge in large animal medicine. J. Vet. Intern. Med. 23, 227-242.

Clark, S. J., Newland, P., Yoxall, C. W. and Subhedar, N. V. (2004): Concentrations of cardiac troponin $\mathrm{T}$ in neonates with and without respiratory distress. Arch. Dis. Child. Fetal Neonatal Ed. 89, F348-F352.

Divers, T. J. (2008): Respiratory diseases. In: Rebhun, W. C. (ed.) Rebhun's Diseases of Dairy Cattle. Elsevier, USA. pp. 79-131.

Eigenmann, U. J., Grunert, E. and Born, E. (1981): Untersuchunger über den Einfluss der Schnittentbindung auf den Säurenbasenhaushalt sowie die Plasmaglukosekonzentration neugeborener Kälbern. Dtsch. Tierärtzl. Wschr. 88, 433-437.

Eigenmann, U. J., Schoon, H. A., Jahn, D. and Grunert, E. (1984): Neonatal respiratory distress syndrome in the calf. Vet. Rec. 114, 141-144.

El-Khuffash, A. F. and Molloy, E. J. (2008): Serum troponin in neonatal intensive care. Neonatology 94, 1-7.

Evans, N. and Kluckow, M. (1996): Early determinants of right and left ventricular output in ventilated preterm infants. Arch. Dis. Child. Fetal Neonatal Ed. 74, 88-94.

Gill, A. B. and Weindling, A. M. (1993): Echocardiographic assessment of cardiac function in shocked very low birthweight infants. Arch. Dis. Child. 68, 17-21.

Gunes, V., Atalan, G., Citil, M. and Erdogan, H. M. (2008): Use of cardiac troponin kits for the qualitative determination of myocardial cell damage due to traumatic reticuloperitonitis in cattle. Vet. Rec. 162, 514-517.

Gunes, V., Erdogan, H. M., Citil, M. and Ozcan, K. (2005): Assay of cardiac troponins in the diagnosis of myocardial degeneration due to foot-and-mouth disease in a calf. Vet. Rec. 156, 714-715.

Guzelbektes, H., Coskun, A., Ok, M., Aydogdu, U. and Sen, I. (2012): Prevalence of gastroesophageal reflux disease in premature calves. J. Vet. Intern. Med. 26, 1051-1055.

Karapinar, T. and Dabak, M. (2008): Treatment of premature calves with clinically diagnosed respiratory distress syndrome. J. Vet. Intern. Med. 22, 462-466.

Karapinar, T., Dabak, D. O., Kuloglu, T. and Bulut, H. (2010): High cardiac troponin I plasma concentration in a calf with myocarditis. Can. Vet. J. 51, 397-399.

Kemp, M., Donovan, J., Higham, H. and Hooper, J. (2004): Biochemical markers of myocardial injury. Br. J. Anaesth. 93, 63-73.

Lopes, D. N., Ramos, J. M. M., Moreira, M. E. L., Cabral, J. A., de Carvalho, M. and de Andrade Lopes, J. M. (2012): Cardiac troponin T and illness severity in the very-low-birth-weight infant. Int. J. Pediatr. 2012, 479242. doi: 10.1155/2012/479242.

Martin-Ancel, A., Garcia-Alix, A., Gaya, F., Cabanas, F., Burgueros, M. and Quero, J. (1995): Multiple organ involvement in perinatal asphyxia. J. Pediatr. 127, 786-793.

Mellanby, R. J., Henry, J. P., Cash, R., Ricketts, S. W., Bexiga, R., Truyers, I. and Mellor, D. J. (2009): Serum cardiac troponin I concentrations in cattle with cardiac and noncardiac disorders. J. Vet. Intern. Med. 23, 926-930.

Möller, J. C., Thielsen, B., Schaible, T. F., Reiss, I., Kohl, M., Welp, T. and Gortner, L. (1998): Value of myocardial hypoxia markers (creatine kinase and its MB-fraction, troponin-T, QT-intervals) and serum creatinine for the retrospective diagnosis of perinatal asphyxia. Biol. Neonate 73, 367-374.

Mu, S., Wang, L. J., Chen, Y. L., Lin, M. I. and Sung, T. C. (2009): Correlation of troponin I with perinatal and neonatal outcomes in neonates with respiratory distress. Pediatr. Int. 51, 548-551.

Ng, P. C. and Lam, H. S. (2012): Biomarkers in neonatology: the next generation of tests. Neonatology 102, 145-151. 
O’Brien, P. J., Dameron, G. W., Beck, M. L., Kang, Y. J., Erickson, B. K., Di Battista, T. H., Miller, K. E., Jackson, K. N. and Mittelstadt, S. (1997a): Cardiac troponin T is a sensitive, specific biomarker of cardiac injury in laboratory animals. Lab. Anim. Sci. 47, 486-495.

O'Brien, P. J., Landt, Y. and Ladenson, J. H. (1997b): Differential reactivity of cardiac and skeletal muscle from various species in a cardiac troponin I immunoassay. Clin. Chem. 43, 2333-2338.

Peek, S. F., Apple, F. S., Murakami, M. A., Crump, P. M. and Semrad, S. D. (2008): Cardiac isoenzymes in healthy Holstein calves and calves with experimentally induced endotoxemia. Can. J. Vet. Res. 72, 356-361.

Pickel, M., Zaremba, W. and Grunert, E. (1989): Comparison of arterial and venous blood gas and acid-base values in prematurely born healthy calves or calves with a late asphyxia (in German). Zbl. Vet-med. A 36, 653-663.

Radostits, O. M., Gay, C. C., Blood, D. C. and Hinchcliff, K. W. (2007): Veterinary Medicine: A Textbook of the Diseases of Cattle, Sheep, Pigs, Goats and Horses. 10th edition. Elsevier, USA. pp. 399-438.

Rajakumar, P. S., Bhat, B. V., Sridhar, M. G., Balachander, J., Konar, B. C., Narayanan, P. and Chetan, G. (2008): Cardiac enzyme levels in myocardial dysfunction in newborns with perinatal asphyxia. Indian J. Pediatr. 75, 1223-1225.

Russell, K. E. and Roussel, A. J. (2007): Evaluation of the ruminant serum chemistry profile. Vet. Clin. Food Anim. 23, 403-426.

Sadoh, W. E. and Eregie, C. O. (2012): Cardiac troponin T as a marker of myocardial injury in a group of asphyxiated African neonates. Paediatr. Int. Child. Health. 32, 43-46.

Sweetman, D., Armstrong, K., Murphy, J. F. A. and Molloy, E. J. (2012): Cardiac biomarkers in neonatal hypoxic ischaemia. Acta Paediatr. 101, 338-343.

Szenci, O., Taverne, M. A. M. and Takács, E. (1989): A review of 126 Caesarean sections by blood gas and acid base status of the newborn calves. Theriogenology 32, 667-673.

Szymankiewicz, M., Matuszczak-Wleklak, M., Vidyasagar, D. and Gadzinowski, J. (2006): Retrospective diagnosis of hypoxic myocardial injury in premature newborns. J. Perinat. Med. 34, 220-225.

Tapia-Rombo, C. A., Carpio-Hernández, J. C., Salazar-Acuña, A. H., Alvarez-Vázquez, E., Mendoza-Zanella, R. M., Pérez-Olea, V. and Rosas-Fernández, C. (2000): Detection of transitory myocardial ischemia secondary to perinatal asphyxia. Arch. Med. Res. 31, 377-383.

Trevisanuto, D., Zaninotto, M., Altinier, S., Plebani, M. and Zanardo, V. (2000a): High serum cardiac troponin $\mathrm{T}$ concentrations in preterm infants with respiratory distress syndrome. Acta Pediatr. 89, 1134-1136.

Trevisanuto, D., Zaninotto, M., Lachin, M., Altinier, S., Plebani, M., Ferrarese, P. and Zanardo, V. (2000b): Effect of patent ductus arteriosus and indomethacin treatment on serum cardiac troponin T levels in preterm infants with respiratory distress syndrome. Eur. J. Pediatr. 159, 273-276.

Tunca, R., Sozmen, M., Erdogan, H., Citil, M., Uzlu, E., Ozen, H. and Gokce, E. (2008): Determination of cardiac troponin I in the blood and heart of calves with foot-and-mouth disease. J. Vet. Diagn. Invest. 20, 598-605.

Undhad, V. V., Fefar, D. T., Jivani, B. M., Gupta, H., Ghodasara, D. J., Joshi, B. P. and Prajapati, K. S. (2012): Cardiac troponin: an emerging cardiac biomarker in animal health. Vet. World 5, 508-511.

Varga, A., Schober, K. E., Holloman, C. H., Stromberg, P. C., Lakritz, J. and Rings, D. M. (2009): Correlation of serum cardiac troponin I and myocardial damage in cattle with monensin toxicosis. J. Vet. Intern. Med. 23, 1108-1116.

Vijlbrief, D. C., Benders, M. J. N. L., Kemperman, H., van Bel, F. and de Vries, W. B. (2012): Cardiac biomarkers as indicators of hemodynamic adaptation during postasphyxial hypothermia treatment. Neonatology 102, 243-248.

Wells, S. M. and Sleeper, M. (2008): Cardiac troponins. J. Vet. Emerg. Crit. Care 18, 235-245. 